\title{
Treatment for Sleep Problems in Children with Autism and Caregiver Spillover Effects
}

\author{
J. Mick Tilford ${ }^{1,2} \cdot$ Nalin Payakachat $^{2} \cdot$ Karen A. Kuhlthau $^{3,4} \cdot$ Jeffrey M. Pyne $^{5} \cdot$ \\ Erica Kovacs $^{6} \cdot$ Jayne Bellando $^{7}$ - D. Keith Williams ${ }^{8}$ - Werner B. F. Brouwer ${ }^{9}$. \\ Richard E. Frye ${ }^{7}$
}

Published online: 1 July 2015

(c) Springer Science+Business Media New York 2015

\begin{abstract}
Sleep problems in children with autism spectrum disorders (ASD) are under-recognized and under-treated. Identifying treatment value accounting for health effects on family members (spillovers) could improve the perceived cost-effectiveness of interventions to improve child sleep habits. A prospective cohort study $(\mathrm{N}=224)$ was conducted with registry and postal survey data completed by the primary caregiver. We calculated quality of life outcomes for the child and the primary caregiver associated with treatments to improve sleep in the child based on prior clinical trials. Predicted treatment effects for melatonin and behavioral
\end{abstract}

J. Mick Tilford

tilfordmickj@uams.edu

1 Department of Health Policy and Management, University of Arkansas for Medical Sciences, Little Rock, AR 72205, USA

2 Division of Pharmaceutical Evaluation and Policy, University of Arkansas for Medical Sciences, Little Rock, AR, USA

3 Department of Pediatrics, Harvard Medical School, Boston, MA, USA

4 Center for Adolescent Health Policy, Massachusetts General Hospital, Boston, MA, USA

5 Center for Mental Healthcare and Outcomes Research, Central Arkansas Veterans Healthcare System and Psychiatric Research Institute, University of Arkansas for Medical Sciences, Little Rock, AR, USA

6 Department of Psychiatry, Columbia University Medical Center, New York, NY, USA

7 Department of Pediatrics, University of Arkansas for Medical Sciences, Little Rock, AR, USA

8 Department of Biostatistics, University of Arkansas for Medical Sciences, Little Rock, AR, USA

9 Department of Health Policy and Management, Erasmus University, Rotterdam, The Netherlands interventions were similar in magnitude for the child and for the caregiver. Accounting for caregiver spillover effects associated with treatments for the child with ASD increases treatment benefits and improves cost-effectiveness profiles.

Keywords Autism spectrum disorder - Child health . Caregiver health · Child sleep habits · Quality adjusted life year $\cdot$ Cost-effectiveness analysis

\section{Introduction}

Economic evaluation complements comparative effectiveness research by assisting in decision making about whether technologies for the treatment or prevention of disease provide good value. Technologies that benefit patients and prove to be cost-effective provide a signal to decisionmakers that the technology warrants translation into practice. Given concerns over the slow uptake of effective technologies by health care systems, some have viewed information from an economic evaluation as a useful tool that can speed up the pace in which interventions are translated or implemented into practice (Glasgow and Emmons 2007; Glasgow and Steiner 2012). Indeed, economic evaluations provide one of the "greatest opportunities" to rapidly translate clinical comparative effectiveness evidence into practice or policy as it provides a clear rationale for decision-makers to act (Glasgow et al. 2013).

The US panel on Cost-Effectiveness in Health and Medicine recommended the use of a societal perspective in economic evaluations (Gold et al. 1996). The societal perspective takes into account all health care costs and benefits created by the intervention irrespective of where they occur in society. Recently, the perspective of 
economic evaluations has broadened to include family effects in the calculation of cost-effectiveness ratios (Basu and Meltzer 2005; Basu et al. 2010; Prosser et al. 2015). Under this perspective, it is recognized that health and medical interventions for patients can have substantial spillover effects on family members in terms of quality adjusted life years (QALYs) gained or lost. The QALY is a standard metric that is recommended for cost-effectiveness analysis by the National Institute for Health and Clinical Excellence (NICE) (2013) and the US Panel on CostEffectiveness in Health and Medicine (Weinstein et al. 1996). It combines the value of health-related quality of life or preference-based health utility and life years gained into a single metric. Failure to account for family spillover effects can bias cost-effectiveness ratios used to inform payers and other decision makers. Effective interventions evaluated solely from the patient perspective can have unfavorable cost-effectiveness ratios that exceed typical threshold values, such as the $\$ 100,000$ per QALY mark, but lie within these thresholds if the intervention confers additional health benefits on the family and these benefits can be accurately measured and incorporated into the economic evaluation.

The potential for health interventions to have spillover effects on the family may be especially pronounced for child health services (Brouwer et al. 2009; Meltzer and Smith 2012). In 1996, the US Panel on Cost-Effectiveness in Health and Medicine included an evaluation of folic acid fortification strategies to illustrate applications involving children. The authors recognized the potential for interventions that prevent spina bifida or other neural tube defects to have health benefits for the family (Kelly et al. 1996). However, the authors (and the panel) recommended against including these benefits in a Reference Case costeffectiveness analysis (CEA) because methods for incorporating family spillover effects were in the early stages of development and data on such spillover effects were not available. Including family spillover effects in the CEA would have increased the QALYs gained for all of the food fortification interventions under study.

Unlike the current guidance in the US, the UK explicitly recommends the inclusion of family spillover effects in a Reference Case CEA. A number of papers have now addressed methods for incorporating spillover effects in economic evaluations (Basu and Meltzer 2005; Basu et al. 2010), yet application of these methods in the literature remain limited (Wittenberg and Prosser 2013). Thus, the purpose of this paper is to provide estimates of the potential QALYs gained by children with autism spectrum disorders (ASD) from treatments for sleep problems, as well as the spillover effects of sleep treatments on their primary caregiver. We hypothesized that sleep treatments have the potential to improve quality of life outcomes as measured by QALYs for both the child with an ASD and their caregiver. Because QALYs can be measured on the same scale, an analysis of gains to children can be directly compared with gains to caregivers to determine their relative importance to overall health gains and potential impact on estimated cost-effectiveness ratios.

\section{Background on Children with ASD}

ASD is a complex neurodevelopmental condition that is defined by impairments in social interaction, communication, and repetitive and stereotyped behaviors and interests (American Psychiatric Association 2000). While individuals with ASD are characterized by a core set of symptoms, there is wide heterogeneity in the severity of the disorder and there are many co-occurring medical conditions that complicate diagnosis, management, and outcome. Children with ASD may have associated problems with aberrant behavior including severe tantrums, noncompliance, destructiveness, and self-injury, as well as psychiatric comorbidities such as anxiety and attention deficit disorder (Arnold et al. 2003; Simonoff et al. 2008). Other common co-occurring conditions include cognitive deficits, epilepsy, gastrointestinal problems, and sleep problems (Levy et al. 2010; Coury et al. 2012; Reynolds and Malow 2011).

Sleep problems are especially problematic, as they may exacerbate the core and related symptoms of ASD (Malow et al. 2012a). Parental reported prevalence of sleep problems in children with ASD range from 44 to $83 \%$ (Krakowiak et al. 2008). Sleep problems have been associated with worsening of problematic daytime behaviors including social skills deficits, attention deficit hyperactivity disorder, and repetitive behaviors (Goldman et al. 2011). Sleep problems in children with ASD are known to affect family functioning that may be related to concomitant parental sleep problems (Malow et al. 2014). Evidence suggests that sleep problems in this population may be under recognized and under treated because of the emphasis on the daytime behavioral issues (Reynolds and Malow 2011). Effective interventions for sleep problems have the potential to improve health outcomes for children with ASD and their families if they are widely adopted within health care systems.

Treatments for sleep problems in children with ASD are limited. Evidence supports the use of behavioral interventions in children with ASD who have sleep problems (Cortesi et al. 2012; Reed et al. 2009; Malow et al. 2012a, 2014) particularly training parents to develop appropriate bedtime hygiene for their affected children. Complementary and alternative medicine such as massage therapy, aromatherapy, and weighted blankets as well as medications such as risperidone and mirtazapine do not have sufficient evidence to support their use in children with ASD (Malow et al. 2012b). Melatonin, which has sleep-promoting and 
chronobiotic properties, is an approved US Food and Drug Administration nutrition supplement that showed promising results in small, randomized controlled trials as a monotherapy or combination with parent-based sleep education (Rossignol and Frye 2011; Cortesi et al. 2012; Malow et al. 2012a). It is relatively safe and well-tolerated in treating sleep problems among children with ASD. In addition, melatonin is an example of a treatment that not only improves sleep, but also results in improvements in behavior and parenting stress (Malow et al. 2012a).

This study quantifies gains in QALYs for children with ASD and their caregivers from interventions to improve sleep in the child. The gain in QALYs for the caregiver represents the potential spillover effects from treatment of the child with ASD and sleep problems. Our goal is to improve the evidence base for assessing the value of sleep interventions in this population in order to increase their adoption within health systems when warranted.

\section{Methods}

\section{Participants and Study Design}

The study used a cross-sectional and prospective design with two sources of data: outcome measures of interest were obtained from a postal survey and combined with clinical data from treatment centers. Participants for the study were recruited through a registry maintained by the Autism Treatment Network (ATN) funded by Autism Speaks. Two sites of the ATN were used for this study: a developmental center in Little Rock, Arkansas, and an outpatient psychiatric clinic at Columbia University Medical Center in New York, New York. All children had a clinical diagnosis of an ASD meeting DSM-IV-TR criteria (e.g., Autistic Disorder, PDD-NOS, or Asperger's Disorder). The sample included families of children with an ASD that agreed to participate in future research studies as part of the ATN. English-speaking families of children with an ASD who were between 4 and 17 years of age were contacted by mail to see if they would be interested in participating in the study. Details on the sampling procedure are reported elsewhere (Payakachat et al. 2014). The institutional review boards at Columbia University and the University of Arkansas for Medical Sciences approved the study.

\section{Patient-reported Outcome Measures}

\section{Preference-based HRQoL Instruments}

Two generic preference-based HRQoL instruments were selected for both caregivers and children because information on which instrument would be most sensitive to changes in sleep problems was not available. In this study, we compared estimates from the HUI-3 (Health Utilities Index Mark 3) (Feeny et al. 2002) and the QWB-SA (Quality Well-being Self-Administered) (Kaplan and Anderson 1996) in children. The HUI-3 has eight domains_-vision, hearing, speech, ambulation, dexterity, emotion, cognition, and pain-each with five or six response levels. This creates a total of 972,000 possible combinations of unique health states that are linked to predetermined preference-weighted scores. The HUI-3 index ranges from -0.36 (some health states are considered worse than dead) to 1 (perfect health state). The HUI-3 was selected because of its psychometric properties (Horsman et al. 2003) and it has been used in many studies involving children including those with autism (Petrou and Kupek 2009; Tilford et al. 2012). The QWB-SA is a self-administered instrument combining three scales of functioning (mobility, physical activity, and social activity including completion of role expectation) with a measure of symptoms and problems to produce a point-in-time expression of well-being that ranges from 0 (death) to 1 (symptomatic full function). It was selected because it has been found to be a sensitive measure for mental health conditions (Pyne et al. 2003) and has been used in children (Smith-Olinde et al. 2008), albeit less frequently. The primary caregivers completed both instruments for their children. For caregivers, the SF-6D (Brazier and Roberts 2004)and EQ-5D (Johnson et al. 1998) were selected as they have been compared frequently in the literature.

\section{Sleep Problems}

The CSHQ (Children's Sleep Habits Questionnaire) was used to assess sleep behaviors and problems in children (parent-reported instrument) (Owens et al. 2000). The original 45-item CSHQ was revised to eliminate redundant or ambiguous items and left with 35 items that can be grouped into eight sleep domains (bedtime resistance, sleep onset delay, sleep duration, sleep anxiety, night wakings, parasomnias, sleep disordered breathing, and daytime sleepiness). A total score was calculated by summing all items of the eight domains, but it consisted of only 33 items because two items on the bedtime resistance and sleep anxiety domains were identical. A higher total score indicates more disturbed sleep. The CSHQ has good psychometric properties and has been used to study sleep problems in children with ASD (Krakowiak et al. 2008; Cortesi et al. 2012). A recent practice guideline recommends using the CSHQ to assess children for sleep problems (Malow et al. $2012 b$ ). For the purpose of this study, a cut-off point of 41 was used to identify children with clinically significant sleep disturbance, based on work done in children with typical development (Owens et al. 2000). The CSHQ was used as 
the main outcome measure in several recent clinical trials (Cortesi et al. 2012; Malow et al. 2012a, 2014).

\section{Other Patient-reported Measures}

A number of other measures were collected to further assess caregiver quality of life and the severity of the child's condition. The CES-D (Center for Epidemiologic Studies Depression Scale) was used to assess depression symptoms in caregivers. It has 20 items with scores ranging from 0 to 60 with higher scores reflecting more depressive symptoms (Radloff 1977). A cut-off point of 16 on the CES-D was used to indicate high level of depressive symptoms. Caregiver burden and well-being was measured using the CarerQol instrument that is comprised of the CarerQol visual analogue scale (CarerQol-VAS) and its descriptive system (CarerQol-7D) (Brouwer et al. 2006). A weighted sum score of the CarerQol-7D ranges from 0 (worst care-related quality of life) to 100 (best care-related quality of life) (Hoefman et al. 2014). The CarerQol-VAS measures well-being of parents in terms of happiness from 0 (completely unhappy) to 10 (completely happy).

\section{Clinical Measures}

The ADOS severity score (range of 1-10) is a calibrated metric that is used to quantify the relative severity of ASD symptoms (Shumway et al. 2012). A higher score represents more severe ASD symptoms. Cognitive ability was measured within the ATN by the Stanford-Binet Intelligence Scales, 5th edition (SB-5), Abbreviated Battery, an individually administered, standardized cognitive assessment that could be used with individuals aged 2 years and older. If the child could not be evaluated on the SB-5, the Mullen Scales of Early Learning, American Guidance Service Edition (Mullen 1997) or the Bayley Scales of Infant Development, 3rd edition (Bayley 2006) were used to assess cognitive functioning. All three cognitive ability measures are in comparison to age-based norms and provide a standard score with a mean of 100 and standard deviation of 15 .

\section{Statistical Analysis}

Demographic information and instrument scores for children with ASD and their caregivers were provided as descriptive statistics. Spearman's rank correlation was employed to explore associations between the CSHQ total score from children with ASD and other instrument scores. We further determined the associations between the CSHQ total scores and health utility scores using ordinary least squares (OLS) regression, controlling for child age, severity of the condition (measured by the ADOS), cognitive ability, and child gender.
Because health utility scores typically have non-normal distributions with negative skew and ceiling effects (a large spike at the upper bound of perfect health), various statistical modeling approaches have been considered including beta regression and two-part models (Brazier et al. 2010). Recent simulation studies found that OLS can produce unbiased estimates under specific circumstances (Pullenayegum et al. 2010). When these circumstances are not met, especially the presence of a large spike at 1 in the health utility score distribution, two-part models and beta regression approaches have been shown to improve model fit over OLS (Basu and Manca 2012).

The distribution of HUI3 and QWB-SA scores in our sample was skewed (skewness of -0.9 and 0.4 ), but only a small percentage of respondent HUI3 scores $(4.1 \%)$ and QWB-SA scores (3.5\%) reached the ceiling of 1 . Thus, the distributions of health utility scores for children with ASD do not correspond to the distribution patterns that benefit from beta regression or other estimation approaches (Basu and Manca 2012). For this reason, we decided to use OLS for analyses involving child outcomes in this study. For caregiver analyses, we compared estimates from the beta quasi-likelihood approach and OLS because of the large ceiling effects $(30.4 \%)$ and skew $(-1.2)$ in the distribution of the EQ-5D. Only one caregiver reported perfect health on the SF6D and skew was minimal $(-0.10)$. Parameter estimates differed by less than $5 \%$ between the alternative estimators, so we reported OLS estimates in all analyses. Model specification was investigated using the Ramsey RESET test (1969) and the Link test (Pregibon 1980).

QALY estimates were generated from two randomized controlled trials that used the CSHQ as a primary outcome measure (Cortesi et al. 2012; Malow et al. 2014). The trials provided estimates in terms of reduced CSHQ scores among children with ASD for four different interventions including melatonin, cognitive behavioral therapy (CBT), combination of melatonin and $\mathrm{CBT}$, and a parent-based sleep intervention. Changes in CSHQ total scores were used to predict one-year QALY gains for both the child and the primary caregiver using the estimated relationships described above. Bootstrapping standard errors and biascorrected $95 \%$ confidence intervals for all OLS estimates are calculated with 1000 replications. SAS 9.3 (SAS Institute, Cary, NC) and Stata/SE 13.0 (StataCorp, College Station, TX) were utilized for all analyses.

\section{Results}

A total of 224 children with ASD and their caregivers participated in this study (response rate of $59.2 \%$ ). Average ages of children and caregivers were $8.2(\mathrm{SD}=3.5)$ and $39.4(\mathrm{SD}=8.3)$ years old, respectively. The majority 
of the children were male $(86.6 \%)$ while the caregivers were mostly female $(89.5 \%)$ with $94.5 \%$ of them being the biological parents of the affected children. One third of the caregivers $(34.8 \%)$ reported annual household income greater than $\$ 100,000$. The demographic characteristics of study participants are provided in Table 1.

Table 2 provides summary outcome measures and correlations with sleep for children with ASD and their caregivers. HUI-3 and QWB-SA scores for children with ASD were $0.659(\mathrm{SD}=0.234)$ and $0.591(\mathrm{SD}=0.164)$ on a scale with 1.0 representing perfect health and 0 representing dead. Both instrument scores were significantly correlated with the CSHQ total scores. Summary statistics from the CSHQ indicated significant sleep problems in this sample with an average score of $49.1(\mathrm{SD}=8.3)$ and $83.1 \%$ reporting total scores $>41$. As hypothesized, CSHQ total scores were significantly and negatively correlated with caregiver sleep hours.

Preference-based HRQoL scores for the caregiver EQ$5 \mathrm{D}$ and SF-6D were $0.847(\mathrm{SD}=0.138)$ and 0.741 $(\mathrm{SD}=0.119)$ reflecting the differences in scale for the two instruments. Both instruments were significantly correlated with the CSHQ and the number of hours of sleep reported by the caregiver. Other measures of health had the hypothesized relationship to the CSHQ and caregiver sleep hours. The CES-D averaged $13.8(\mathrm{SD}=10.6)$ with $39.3 \%$ reaching the threshold (CESD scores $\geq 16$ ) for depressive symptoms. Both the CarerQol-7D and CarerQol-VAS indicated negative care-related quality of life and wellbeing effects on the caregiver associated with sleep problems in the child.

Table 3 provides summary outcome scores for both the child and caregiver by hours of sleep as reported by the primary caregiver. Reported hours of sleep were categorized by $\leq 5 \mathrm{~h}$ of sleep, $6 \mathrm{~h}$ of sleep, $7 \mathrm{~h}$ of sleep, and $\geq 8 \mathrm{~h}$ of sleep per night. Approximately $25 \%$ of caregivers reported sleeping $\leq 5 \mathrm{~h}$ per night and more than half reported sleeping $6 \mathrm{~h}$ or less. In general, child and caregiver outcomes followed a step function in relation to reported hours of sleep with all tests for trend significant at the $p$ value of 0.01 with the exception of the HUI-3 score $(p=0.052)$. CSHQ scores were highest $(52.9 ; 95 \% \mathrm{CI}$
Table 1 Demographic characteristics of children with ASDs and their caregivers $(\mathrm{n}=224)$

\begin{tabular}{|c|c|c|}
\hline & Children with ASDs ${ }^{\mathrm{a}}$ & Caregivers $^{\mathrm{b}}$ \\
\hline Age, mean \pm SD (range) & $8.2 \pm 3.5(4.0-17.9)$ & $39.4 \pm 8.3(21.6-61.0)$ \\
\hline \multicolumn{3}{|l|}{ Gender } \\
\hline Male & $86.6 \%$ & $10.5 \%$ \\
\hline Female & $13.4 \%$ & $89.5 \%$ \\
\hline \multicolumn{3}{|l|}{ Race/ethnicity } \\
\hline Caucasian & $75.2 \%$ & $72.8 \%$ \\
\hline African American & $9.2 \%$ & $9.4 \%$ \\
\hline Hispanic & $9.2 \%$ & $10.8 \%$ \\
\hline Asian & $2.3 \%$ & $3.3 \%$ \\
\hline Other & $4.1 \%$ & $3.3 \%$ \\
\hline \multicolumn{3}{|l|}{ Relationship to the child } \\
\hline Biological parent & & $94.9 \%$ \\
\hline Divorced & & $10.0 \%$ \\
\hline \multicolumn{3}{|l|}{ Education } \\
\hline High school or lower & & $8.5 \%$ \\
\hline Some college or higher & & $91.5 \%$ \\
\hline \multicolumn{3}{|l|}{ Income } \\
\hline$<\$ 20,000$ & & $14.2 \%$ \\
\hline$\$ 20,000-\$ 35,000$ & & $12.7 \%$ \\
\hline$\$ 35,000-\$ 60,000$ & & $15.7 \%$ \\
\hline$\$ 60,000-\$ 100,00$ & & $22.5 \%$ \\
\hline$>\$ 100,000$ & & $34.8 \%$ \\
\hline \multicolumn{3}{|l|}{ Employment status } \\
\hline Part-time or full-time & & $61.7 \%$ \\
\hline Not employed & & $38.3 \%$ \\
\hline
\end{tabular}


Table 2 Descriptive statistics and correlations between health measures, CSHQ scores, and caregiver sleep hours

\begin{tabular}{|c|c|c|c|c|}
\hline & $\mathrm{N}$ & Mean \pm SD (range) & $\begin{array}{l}\text { Spearman correlations } \\
\text { with CSHQ summary scores }\end{array}$ & $\begin{array}{l}\text { Spearman correlations } \\
\text { with caregiver sleep hours }\end{array}$ \\
\hline \multicolumn{5}{|l|}{ Child } \\
\hline HUI-3 score & 218 & $\begin{array}{l}0.659 \pm 0.234 \\
(-0.098-1.0)\end{array}$ & $-0.177^{*}$ & 0.123 \\
\hline QWB-SA score & 224 & $\begin{array}{l}0.591 \pm 0.164 \\
(0.182-1.0)\end{array}$ & $-0.228^{*}$ & $0.179^{*}$ \\
\hline CSHQ summary score & 202 & $\begin{array}{l}49.1 \pm 8.4 \\
(35-84)\end{array}$ & 1.000 & $-0.270 * *$ \\
\hline CSHQ score $>41^{\mathrm{b}}$ & 163 & $83.1 \%$ & & \\
\hline \multicolumn{5}{|l|}{ Caregiver } \\
\hline EQ-5D score & 219 & $\begin{array}{l}0.847 \pm 0.139 \\
(0.308-1.0)\end{array}$ & $-0.227^{*}$ & $0.305 * *$ \\
\hline SF-6D score & 213 & $\begin{array}{l}0.741 \pm 0.119 \\
(0.378-1.0)\end{array}$ & $-0.285^{* *}$ & $0.261^{*}$ \\
\hline CES-D & 203 & $\begin{array}{l}13.8 \pm 10.6 \\
(0-55)\end{array}$ & $-0.256^{* *}$ & $-0.345^{* *}$ \\
\hline $\mathrm{CES}-\mathrm{D} \geq 16^{\mathrm{a}}$ & 84 & $39.3 \%$ & & \\
\hline CarerQol-7D & 215 & $\begin{array}{l}75.0 \pm 19.7 \\
(15.3-100)\end{array}$ & $-0.244 * *$ & $-0.344 * *$ \\
\hline CarerQol-VAS (Happiness scale) & 215 & $\begin{array}{l}7.4 \pm 1.9 \\
(0-10)\end{array}$ & $-0.216^{*}$ & $0.299 * *$ \\
\hline
\end{tabular}

$S D$ standard deviation, $C S H Q$ Children's Sleep Habits Questionnaire, HUI-3 Health Utilities Index Mark 3, $Q W B$-SA Quality of Well-Being SelfAdministered, $E Q-5 D$ 5-Dimension EuroQol, $S F-6 D$ 6-Dimension Short-Form, $C E S-D$ Center for Epidemiologic Studies Depression Scale, CarerQol-7D 7-Dimension Care-related Quality of Life, CarerQol-VAS Care-related Quality of life Visual Analog Scale

${ }^{a}$ CES-D score $\geq 16$ indicates clinical depressive symptoms

${ }^{\mathrm{b}}$ CSHQ summary score $>41$ indicates significant sleep problems

Table 3 Health outcomes of children with ASDs and caregivers by self-reported number of caregiver sleep hours

\begin{tabular}{|c|c|c|c|c|c|c|c|c|c|}
\hline \multirow{2}{*}{$\begin{array}{l}\text { Sleep } \\
\text { hours }\end{array}$} & \multirow{2}{*}{$\begin{array}{l}\mathrm{N} \\
(\%)\end{array}$} & \multicolumn{3}{|c|}{ Child outcomes (LSMEAN, $95 \%$ CL) } & \multicolumn{5}{|c|}{ Caregiver outcomes (LSMEAN, $95 \%$ CL) } \\
\hline & & $\begin{array}{l}\text { CSHQ } \\
\text { Score }\end{array}$ & $\begin{array}{l}\text { HUI3 } \\
\text { Score }\end{array}$ & $\begin{array}{l}\text { QWB-SA } \\
\text { Score }\end{array}$ & $\begin{array}{l}\text { SF-6D } \\
\text { Score }\end{array}$ & $\begin{array}{l}\text { EQ-5D } \\
\text { Score }\end{array}$ & $\begin{array}{l}\text { CES-D } \\
\text { Score }\end{array}$ & $\begin{array}{l}\text { CarerQol } \\
\text { 7D }\end{array}$ & CarerQolVAS \\
\hline$\leq 5 \mathrm{~h}$ & $\begin{array}{l}55 \\
(24.9 \%)\end{array}$ & $\begin{array}{l}52.2 \\
(48.9-55.3)\end{array}$ & $\begin{array}{l}0.580 \\
(0.494-0.677)\end{array}$ & $\begin{array}{l}0.533 \\
(0.476-0.598)\end{array}$ & $\begin{array}{l}0.710 \\
(0.670-0.756)\end{array}$ & $\begin{array}{l}0.785 \\
(0.743-0.839)\end{array}$ & $\begin{array}{l}18.0 \\
(14.0-22.0)\end{array}$ & $\begin{array}{l}62.6 \\
(55.6-69.6)\end{array}$ & $\begin{array}{l}6.6 \\
(5.9-7.3)\end{array}$ \\
\hline $6 \mathrm{~h}$ & $\begin{array}{l}57 \\
(25.8 \%)\end{array}$ & $\begin{array}{l}48.4 \\
(45.0-51.5)\end{array}$ & $\begin{array}{l}0.640 \\
(0.555-0.739)\end{array}$ & $\begin{array}{l}0.533 \\
(0.475-0.600)\end{array}$ & $\begin{array}{l}0.738 \\
(0.698-0.786)\end{array}$ & $\begin{array}{l}0.847 \\
(0.803-0.903)\end{array}$ & $\begin{array}{l}14.0 \\
(9.9-18.0)\end{array}$ & $\begin{array}{l}72.4^{*} \\
(65.3-79.6)\end{array}$ & $\begin{array}{l}7.4 \\
(6.8-8.2)\end{array}$ \\
\hline $7 \mathrm{~h}$ & $\begin{array}{l}75 \\
(33.9 \%)\end{array}$ & $\begin{array}{l}47.8^{*} \\
(44.8-50.5)\end{array}$ & $\begin{array}{l}0.628 \\
(0.555-0.717)\end{array}$ & $\begin{array}{l}0.570 \\
(0.520-0.631)\end{array}$ & $\begin{array}{l}0.783 * * \\
(0.748-0.826)\end{array}$ & $\begin{array}{l}0.888 * * \\
(0.851-0.940)\end{array}$ & $\begin{array}{l}8.8 * * \\
(5.2-12.4)\end{array}$ & $\begin{array}{l}78.8 * * \\
(72.4-85.1)\end{array}$ & $\begin{array}{l}7.9 * * \\
(7.4-8.7)\end{array}$ \\
\hline$\geq 8 \mathrm{~h}$ & $\begin{array}{l}34 \\
(15.4 \%)\end{array}$ & $\begin{array}{l}44.6^{* *} \\
(40.6-48.4)\end{array}$ & $\begin{array}{l}0.685 \\
(0.578-0.798)\end{array}$ & $\begin{array}{l}0.619 \\
(0.546-0.698)\end{array}$ & $\begin{array}{l}0.795 * * \\
(0.744-0.852)\end{array}$ & $\begin{array}{l}0.923 * * \\
(0.866-0.987)\end{array}$ & $\begin{array}{l}7.8 * * \\
(3.0-12.5)\end{array}$ & $\begin{array}{l}80.2 * * \\
(71.5-89.0)\end{array}$ & $\begin{array}{l}8.1 * * \\
(7.3-9.0)\end{array}$ \\
\hline
\end{tabular}

LSMEAN = Least squared mean, controlling for parent age, parent gender, child age, child gender and their $95 \%$ confidence limits

$S D$ standard deviation, CSHQ Children's Sleep Habits Questionnaire, HUI-3 Health Utilities Index Mark 3, $Q W B$-SA Quality of Well-Being SelfAdministered, EQ-5D 5-Dimension EuroQol, SF-6D 6-Dimension Short-Form, CES-D Center for Epidemiologic Studies Depression Scale, CarerQol-7D 7-Dimension Care-related Quality of Life, CarerQol-VAS Care-related Quality of life Visual Analog Scale

$* p<0.05$, compared to parents who reported number of sleep at night $\leq 5 \mathrm{~h}$

** $p<0.001$, compared to parents who reported number of sleep at night $\leq 5 \mathrm{~h}$ 
48.9-55.3) for caregivers who reported sleeping the least after adjusting for age and gender and were significantly lower for caregivers who reported more sleep.

Consistent with our main hypothesis, lower health utility scores for the child and poorer health status for the primary caregiver were associated with child sleep problems. Caregivers who reported that they slept $\leq 5 \mathrm{~h}$ per night had significantly lower SF-6D and EQ-5D scores and CarerQol-VAS scores than caregivers who slept 7 and $\geq 8 \mathrm{~h}$ per night. We also found that caregivers who reported that they slept $\leq 5 \mathrm{~h}$ per night had significantly higher CES-D and lower CarerQol-7D scores suggesting the presence of more depressive symptoms and worse quality of life. Indeed, $58.3 \%$ of caregivers met the threshold for clinically depressive symptoms if they slept $\leq 5 \mathrm{~h}$ per night and $48.1 \%$ met the threshold if they slept $6 \mathrm{~h}$ per night. This percentage fell to 26.5 and $27.3 \%$ if caregivers slept 7 or $8 \mathrm{~h}$ or more per night.

Table 4 provides OLS regression coefficients for relationships between the CSHQ total scores and the health utility scores for the child and caregiver after controlling for age, gender, cognitive ability, and the severity of the ASD. Estimates are presented as one-unit changes in the
CSHQ effect on the utility scores for the different instruments. To put the estimates into perspective, a standard deviation decrease in the CSHQ total score of 8.4 points (indicating better sleep habits) leads to a clinically significant increase in the child's HUI-3 score by 0.036 points. The same change in the CSHQ also generates an increase in the caregiver's SF-6D score of 0.035 points, suggesting a potential gain in QALYs that doubles when effects on the caregivers are included.

Table 5 summarizes CSHQ total scores at baseline and following treatment in two randomized trials that examined the effect of melatonin, cognitive behavioral therapy (CBT), combination of melatonin and CBT, and parentbased sleep education. Associated QALY gains for the child and the caregiver are presented based on differences in CSHQ total scores from the treatment. The trial by Cortesi et al. (2012) found large improvements in CSHQ total scores from treatment with melatonin $(-11.9)$ and the combination of melatonin and CBT $(-18.3)$ that translate into large QALY gains for both the child and the caregiver. For melatonin, one-year QALY gains equaled 0.049 (95\% CI $0.047-0.51)$ for the child and $0.050 \quad(95 \%$ CI 0.035-0.064) for the caregiver. Melatonin and CBT

Table 4 Estimated effect of CSHQ total scores on child and caregiver utility measures

\begin{tabular}{lllllll}
\hline Measure & CSHQ beta & $\begin{array}{l}\text { Bootstrap } \\
\text { standard error }\end{array}$ & $\begin{array}{l}\text { Bias-corrected } \\
95 \% \text { confidence interval }\end{array}$ & Adjusted R ${ }^{2}$ & $\begin{array}{l}\text { Link test } \\
(p \text { value })\end{array}$ & $\begin{array}{l}\text { Ramsey reset test } \\
(p \text { value })\end{array}$ \\
\hline $\begin{array}{l}\text { Child } \\
\text { HUI3 }\end{array}$ & $-0.0043^{*}$ & 0.0019 & $-0.0081,-0.0005$ & 0.168 & 0.182 & 0.396 \\
QWB-SA & $-0.0045^{* *}$ & 0.0013 & $-0.0071,-0.0021$ & 0.076 & 0.398 & 0.400 \\
Caregiver & & & & & 0.073 & 0.334 \\
SF6D & $-0.0042^{* *}$ & 0.0011 & $-0.0064,-0.0021$ & 0.077 & 0.910 & 0.090 \\
EQ5D & $-0.0038^{*}$ & 0.0015 & $-0.0069,-0.0010$ & & & \\
\hline
\end{tabular}

${ }^{a}$ OLS regression controlling for ADOS, $\log (\mathrm{IQ})$, child age, child gender

${ }^{\mathrm{b}}$ OLS regression controlling for ADOS, $\log (\mathrm{IQ})$, caregiver age and gender

c Bootstrapping standard error with 1000 replications

$* p<0.05$

$* * p<0.001$

Table 5 Estimated child and spillover QALYs gained from alternative treatments for sleep problems in children with ASD

\begin{tabular}{llllll}
\hline Treatment & $\begin{array}{l}\text { Baseline } \\
\text { CSHQ }\end{array}$ & $\begin{array}{l}\text { Treatment } \\
\text { CSHQ }\end{array}$ & $\begin{array}{l}\text { Mean difference } \\
\text { (pooled SD) }^{-}\end{array}$ & $\begin{array}{l}\text { Child } \\
\text { QALYs gained } \\
\text { Mean (95\% CI) }\end{array}$ & $\begin{array}{l}\text { Caregiver spillover } \\
\text { QALYs gained } \\
\text { Mean (95\% CI) }\end{array}$ \\
\hline Melatonin (Malow et al. 2014) & $66.7(8.6)$ & $54.8(6.2)$ & $-11.9(7.48)$ & $0.049(0.047-0.051)$ & $0.050(0.035-0.064)$ \\
CBT (Malow et al. 2014) & $64.5(5.5)$ & $60.1(4.7)$ & $-4.4(5.11)$ & $0.017(0.017-0.019)$ & $0.019(0.018-0.020)$ \\
Melatonin and CBT (Malow et al. 2014) & $66.1(5.5)$ & $47.8(2.9)$ & $-18.3(4.39)$ & $0.076(0.072-0.080)$ & $0.078(0.075-0.080)$ \\
$\begin{array}{l}\text { Parent-based sleep education (Cortesi } \\
\text { et al. 2012) }\end{array}$ & $55.8(8.1)$ & $49.3(8.2)$ & $-6.2(8.0)$ & $0.025(0.023-0.026)$ & $0.026(0.025-0.028)$ \\
\hline
\end{tabular}

${ }^{a}$ Estimates assume 1-year treatment gain for comparability using bootstrap with 1000 replications with $95 \%$ bias-corrected confidence interval; based on author calculations from information in table 
generated QALY gains of 0.076 (95 \% CI 0.072-0.080) for the child and 0.078 (95\% CI 0.075-0.080) for the caregiver. Interestingly, the incremental improvement in CSHQ scores from the combination of CBT and melatonin over melatonin alone $(-6.4)$ is similar to the improvement in CSHQ total scores reported by Malow et al. (2014) (-6.5) where $15 \%$ of children were on melatonin and others could have initiated melatonin prior to enrollment in the trial.

\section{Discussion}

The goal of this study was to quantify the importance of sleep problems on the health of children with ASD and their primary caregiver using the QALY metric to enable identification of potential spillover effects on the caregiver from successful treatment of the child. Evidence on the effectiveness of treatment for sleep problems in children with ASD has been established in prior studies using the CSHQ as a primary outcome measure (Cortesi et al. 2012; Malow et al. 2014). Both treatment with melatonin and behavioral interventions can improve the sleep habits and the health of the child with ASD. The evidence also indicates that effective treatment for the child can improve health outcomes for caregivers (Malow et al. 2012a). However, evidence on the potential cost-effectiveness of treatment, especially behavioral treatments for sleep problems in children with ASD, is lacking. Without such evidence, effective treatments may not become part of routine practice or may require much more time for such treatments to become routine practice. Thus, this study provides new information on the potential QALYs gained to the child with ASD from treatment of sleep problems and the spillover QALYs to the caregiver that can be used in cost-effectiveness evaluations to aid decision-making.

Our findings have substantial implications for cost-effectiveness evaluations of sleep treatment for children with ASD and other populations as well. We estimate that the spillover QALYs gained by the caregiver are of similar magnitude as the gains to the child. Cost-effectiveness evaluations from the patient perspective that ignore these spillover benefits will therefore greatly understate the benefits of treatment and worsen the estimated cost-effectiveness ratio. Indeed, in the context of treatment for sleep problems in children with ASD, the spillover effect is large with QALY gains approximately double from gains based solely on the child and calls into question cost-effectiveness analysis conducted from the perspective of the patient in this population of children and other similar contexts.

The US panel on Cost-Effectiveness in Health and Medicine acknowledged the potential for spillover effects to influence estimated cost-effectiveness ratios, but recommended against their inclusion in a reference case analysis because data and methods for incorporating such effects were lacking (Kelly et al. 1996). The last decade has witnessed substantial progress in methods for incorporating caregiver and family effects in economic evaluations (Tilford and Payakachat 2014). Basu and Meltzer (2005) and Basu et al. (2010) provided necessary theoretical guidance to focus the discussion of family effects and economic evaluation, but data from applications to specific conditions and treatments remain limited. In attempting to demonstrate the real value of health interventions, and given the development in knowledge and methods, the aim of economic evaluation should be to include family effects whenever relevant. Wittenberg and Prosser (2013) recently published a systematic review of studies that specifically examined spillover effects or permitted calculation of such effects and found seven studies that directly estimated effects and eight studies where effects could be inferred. In general, the findings showed a range of effects from nonexistent to large with estimates varying in relation to condition, age group, and methodology.

Because this study includes clinical measures in relation to health utility measures, we can estimate potential spillover effects of treatment for sleep problems in children with ASD. The cost-effectiveness findings are unequivocal for treatment with melatonin; it is a low cost, safe, and efficacious supplement. However, the incremental cost-effectiveness of behavioral therapy to improve sleep over melatonin alone requires formal evaluation, as it likely is more expensive in both time and resources. Our findings suggest that a cost-effectiveness evaluation at the patient level would generate approximately 0.03 QALYs per year for the child (assuming the intervention has benefits that extend beyond the duration of the trial). While this gain in QALYs meets the definition of clinically important, such an evaluation would greatly understate the true benefits by ignoring the health benefits to the caregiver. The findings suggest an additional gain in caregiver spillover QALYs of a similar magnitude (approximately 0.03 QALYs). Hence, a family perspective produces cost-effectiveness ratios approximately half as large of those from a patient perspective. Cost-effectiveness evidence for behavioral interventions associated with sleep problems may indicate good value, but suggest otherwise if family effects are ignored.

Beyond the findings related to spillover QALYs, this study illustrates the need for greater understanding of sleep problems in children with ASD and the health effects on caregivers. In this sample of medically diagnosed children, we found that $88 \%$ met the threshold for sleep problems based on the CSHQ, which was on the high end of prior estimates for this population (Krakowiak et al. 2008). Population-based studies typically find that $23 \%$ of typically developed children will meet this threshold (Owens 
et al. 2000). The cutoff point for sleep problems among children with ASD may be different. In addition, we found that approximately $25 \%$ of caregivers in this study report sleeping 5 or fewer hours per night with $60 \%$ of them reporting CES-D scores above the threshold for identifying individuals at risk for clinical depression. Data from the 2013 American Time Use Survey indicate that approximately $3.5 \%$ of parents sleep five or fewer hours a day (Bureau of Labor Statistics 2014). Our findings contribute to prior research on maternal quality of life and risk for depression that sought to identify which mothers of children with ASD are at most risk for depression (Zablotsky et al. 2013). Our results are not intended to suggest a causal relationship between sleep and depression, as we recognize the limitations of cross-sectional data and the potential for relationships to be recursive as described by Zablotsky et al. (2013). Still, sleep problems in this population and the associated implications for caregivers with respect to their own sleep habits and health deserve broader recognition and intervention where warranted.

Estimates of caregiver spillover effects associated with child sleep problems were based on generic instruments for measuring health utility. Generic instruments may not be sufficiently sensitive to capture health-related quality of life effects in caregivers and other family members. For this reason, we chose to compare findings from two instruments, as there was no guidance in the literature. Estimates of potential QALYs gained by caregivers from sleep treatments for the child were similar irrespective of whether the EQ-5D or the SF-6D was used to measure spillover effects. Interestingly, one study evaluated whether adding a domain for sleep would improve the sensitivity of the EQ-5D because of the recognition of the importance of sleep to health (Yang et al. 2014). The findings did not indicate any improvement over the original instrument.

The major limitation of the current study is the crosssectional design used to estimate potential QALYs gained. Prior research established the efficacy of treatment for sleep problems; our study provides models to quantify the QALYs gained from these treatments. Since our estimated relationships are robust to instrument selection and modeling approach, we have confidence that our QALY estimates for the child and the caregiver qualify as necessary data that can be used in cost-effectiveness applications. Direct collection of evidence in the context of an ongoing intervention remains a priority, especially in relation to specific interventions for targeted sleep problems (night wakings versus sleep onset delay for example).

Another limitation is that we use caregiver responses to measure the health-related quality of life of the child as well as self-reported sleep problems and sleep hours. Direct measures of sleep duration such as autography would have strengthened the study (Lichstein et al. 2006). Issues in conducting economic evaluation in children have been recognized (Ungar and Gerber 2010) and new methods and instruments are being developed in response to these challenges (Prosser et al. 2007). Given the symptoms associated with ASD, few alternatives to caregiver report of health related quality of life exist (Payakachat et al. 2012) and most studies of children with neurodevelopment disorders rely on this methodology to generate estimates of cost-effectiveness. Our prior research has established that caregiver reported HUI-3 scores in particular are strongly correlated with other outcome measures used in ASD research (Tilford et al. 2012).

The potential importance and implications of family spillover effects for cost-effectiveness evaluations are now recognized and warrant serious discussion in decisions regarding the allocation of health resources. Incorporating spillover effects in cost-effectiveness evaluations has the potential to greatly alter estimated cost-effectiveness ratios of interventions and hence, change decisions regarding their use and implementation. While incorporation of family effects may make the actual conduct of cost-effectiveness analysis more difficult, the results presented here suggest it can drastically improve the accuracy of estimated health effects from interventions. Incorporating family effects may be better aligned with constituent understanding of ASD, leading to more useful application and appreciation for cost-effectiveness evaluation of services to treat children affected with the condition (Tilford and Payakachat 2014).

Health research based on QALYs provide an important metric to identify value especially as it allows for incorporating family spillover effects to ensure that the full value of health resources are included in decision-making. Widespread implementation of interventions for managing sleep problems in children with ASD has the potential to improve their health and well-being as well as their caregivers. In addition, better health of caregivers may benefit a broader society as they could maintain their productivity, better job performance, and potentially decrease health care cost (Swanson et al. 2011). Our study confirms that decisions on whether to implement behavioral treatments for sleep problems in children with ASD or other conditions with a similar context, should incorporate family spillover effects to identify their full value.

Acknowledgments The project was supported by a Grant (R01MH089466) with JMT and KAK serving as principal investigators and a Grant (R03MH102495) with NP as the principal investigator both from the National Institute of Mental Health. The content of this article is solely the responsibility of the authors and does not necessarily represent the official views of the National Institute of Mental Health or the National Institutes of Health. The authors acknowledge the members of the Autism Treatment Network for use 
of the data. The data for the study were collected as part of the Autism Treatment Network, a program of Autism Speaks. Further support came from a cooperative agreement (UA3MC11054) from the US Department of Health and Human Services, Health Resources and Services Administration, Maternal and Child Health Research Program, to the Massachusetts General Hospital. The work described in this article represents the independent efforts of the authors with no restrictions from the funding source or the Autism Treatment Network. None of the authors of this study reported a conflict of interest associated with the preparation of the manuscript. Maria Melguizo, Nupur Chowdhury, Rebecca Rieger and Latunja Sockwell provided excellent research assistance.

\section{Compliance of ethical standards}

Conflict of interest The authors declare they have no conflict of interest associated with the manuscript.

Human and animal rights All procedures performed in studies involving human participants were in accordance with the ethical standard of the institutional research committees of the participating institutions and with the 1964 Helsinki declaration and its later amendments or comparable ethical standards.

Informed consent Informed consent was obtained from all individual participants included in the study.

\section{References}

American Psychiatric Association. (2000). Diagnostic and statistical manual of mental disorders (4th ed., text rev). Washington, DC: American Psychiatric Association.

Arnold, L. E., Vitiello, B., McDougle, C., Scahill, L., Shah, B., Gonzalez, N. M., et al. (2003). Parent-defined target symptoms respond to risperidone in RUPP autism study: customer approach to clinical trials. Journal of the American Academy of Child and Adolescent Psychiatry, 42, 1443-1450.

Basu, A., Dale, W., Elstein, A., \& Meltzer, D. (2010). A Time Tradeoff Method for Eliciting Partner's Quality of Life due to Patient's Health States in Prostate Cancer. Medical Decision Making, 30, 355-365.

Basu, A., \& Manca, A. (2012). Regression estimators for generic health-related quality of life and quality-adjusted life years. Medical Decision Making, 32, 56-69.

Basu, A., \& Meltzer, D. (2005). Implications of spillover effects within the family for medical cost-effectiveness analysis. Journal of Health Economics, 24, 751-773.

Bayley, N. (2006). Bayley scales of infant and toddler developmentthird edition. San Antonio, TX: Harcourt Assessment.

Brazier, J. E., \& Roberts, J. (2004). The estimation of a preferencebased measure of health from the SF-12. Medical Care, 42, 851-859.

Brazier, J. E., Yang, Y., Tsuchiya, A., \& Rowen, D. L. (2010). A review of studies mapping (or cross walking) non-preference based measures of health to generic preference-based measures. The European Journal of Health Economics, 11, 215-225.

Brouwer, W., van Exel, N., \& Tilford, J. (2009). Incorporating caregiver and family effects in economic evaluations of child health. In W. J. Ungar (Ed.), Economic evaluation in child health (pp. 55-76). New York: Oxford University Press.

Brouwer, W. B. F., van Exel, N. J. A., van Gorp, B., \& Redekop, W. K. (2006). The CarerQol instrument: A new instrument to measure care-related quality of life of informal caregivers for use in economic evaluations. Quality of Life Research, 15, 1005-1021.
Bureau of Labor Statistics, U. S. D. o. L. (2014). American time use survey-2013 results (Rep. No. USDL-14-1137). http://www. bls.gov/news.release/pdf/atus.pdf

Cortesi, F., Giannotti, F., Sebastiani, T., Panunzi, S., \& Valente, D. (2012). Controlled-release melatonin, singly and combined with cognitive behavioural therapy, for persistent insomnia in children with autism spectrum disorders: A randomized placebo-controlled trial. Journal of Sleep Research, 21, 700-709.

Coury, D. L., Ashwood, P., Fasano, A., Fuchs, G., Geraghty, M., Kaul, A., et al. (2012). Gastrointestinal conditions in children with autism spectrum disorder: Developing a research agenda. Pediatrics, 130, S160-S168.

Feeny, D., Furlong, W., Torrance, G. W., Goldsmith, C. H., Zhu, Z., DePauw, S., et al. (2002). Multiattribute and single-attribute utility functions for the Health Utilities Index Mark 3 system. Medical Care, 40, 113-128.

Glasgow, R. E., Doria-Rose, V. P., Khoury, M. J., Elzarrad, M., Brown, M. L., \& Stange, K. C. (2013). Comparative effectiveness research in cancer: What has been funded and what knowledge gaps remain? Journal of the National Cancer Institute, 105, 766-773.

Glasgow, R. E., \& Emmons, K. M. (2007). How can we increase translation of research into practice? Types of evidence needed. Annual Review of Public Health, 28, 413-433.

Glasgow, R. E., \& Steiner, J. F. (2012). Comparative effectiveness research to accelerate translation: Recommendations for an emerging field of science. In R. C. Brownson, G. A. Colditz, \& E. K. Proctor (Eds.), Dissemination and implementation research in health (pp. 72-92). New York, NY: Oxford University Press.

Gold, M., Siegel, J., Russell, L., \& Weinstein, M. (1996). Cost effectiveness in health and medicine. New York, NY: Oxford University Press.

Goldman, S. E., McGrew, S., Johnson, K. P., Richdale, A. L., Clemons, T., \& Malow, B. A. (2011). Sleep is associated with problem behaviors in children and adolescents with autism spectrum disorders. Research in Autism Spectrum Disorders, 5, $1223-1229$.

Hoefman, R. J., van, E. J., Rose, J. M., van de Wetering, E. J., \& Brouwer, W. B. (2014). A discrete choice experiment to obtain a tariff for valuing informal care situations measured with the CarerQol instrument. Medical Decision Making, 34, 84-96.

Horsman, J., Furlong, W., Feeny, D., \& Torrance, G. (2003). The Health Utilities Index (HUI(R)): Concepts, measurement properties and applications. Health and Quality of Life Outcomes, 1, 54.

Johnson, J. A., Coons, S. J., Ergo, A., \& Szava-Kovats, G. (1998). Valuation of EuroQOL (EQ-5D) health states in an adult US sample. Pharmacoeconomics, 13, 421-433.

Kaplan, R., \& Anderson, J. (1996). The general health policy model: An integrated approach. In B. Spiker (Ed.), Quality of life and pharmacoeconomics in clinical trials (2nd ed., pp. 309-322). Philadelphia, PA: Lippincott-Raven Publishers.

Kelly, A., Haddix, A., Scanlon, K., Helmick, C., \& Mulinare, J. (1996). Cost-effectiveness of strategies to prevent neural tube defects. In J. E. Siegel, L. B. Russell, M. C. Weinstein, \& M. R. Gold (Eds.), Cost-effectiveness in health and medicine (pp. 312-349). New York, Oxford: Oxford University Press.

Krakowiak, P., Goodlin-Jones, B., Hertz-Picciotto, I., Croen, L. A., \& Hansen, R. L. (2008). Sleep problems in children with autism spectrum disorders, developmental delays, and typical development: A population-based study. Journal of Sleep Researh, 17, 197-206.

Levy, S. E., Giarelli, E., Lee, L. C., Schieve, L. A., Kirby, R. S., Cunniff, C., et al. (2010). Autism spectrum disorder and co-occurring developmental, psychiatric, and medical conditions among children in multiple populations of the United States. Journal of Developmental and Behavioral Pediatrics, 31, 267-275. 
Lichstein, K. L., Stone, K. C., Donaldson, J., Nau, S. D., Soeffing, J. P., Murray, D., et al. (2006). Actigraphy validation with insomnia. Sleep, 29, 232-239.

Malow, B., Adkins, K., McGrew, S., Wang, L., Goldman, S., Fawkes, D., et al. (2012a). Melatonin for sleep in children with autism: A controlled trial examining dose, tolerability, and outcomes. Journal of Autism and Developmental Disorders, 42, 1729-1737.

Malow, B. A., Adkins, K. W., Reynolds, A., Weiss, S. K., Loh, A., Fawkes, D., et al. (2014). Parent-based sleep education for children with autism spectrum disorders. Journal of Autism and Developmental Disorders, 44, 216-228.

Malow, B. A., Byars, K., Johnson, K., Weiss, S., Bernal, P., Goldman, S. E., et al. (2012b). A practice pathway for the identification, evaluation, and management of insomnia in children and adolescents with autism spectrum disorders. Pediatrics, 130, S106-S124.

Meltzer, D., \& Smith, P. (2012). Theoretical issues relevant to the economic evaluation of health technologies. In M. V. Pauly, T. G. McGuire, \& P. P. Barros (Eds.), Handbook of health economics (Vol. 2, pp. 433-470). Oxford, UK: North Holland.

Mullen, E. (1997). Mullen Scales of early learning. Los Angeles, CA: Western Psychological Services.

Owens, J. A., Spirito, A., \& McGuinn, M. (2000). The Children's Sleep Habits Questionnaire (CSHQ): Psychometric properties of a survey instrument for school-aged children. Sleep, 23, 1043-1051.

Payakachat, N., Tilford, J. M., Kovacs, E., \& Kuhlthau, K. (2012). Autism spectrum disorders: A review of measures for clinical, health services and cost-effectiveness applications. Expert Review of Pharmacoeconomics \& Outcomes Research, 12, 485-503.

Payakachat, N., Tilford, J. M., Kuhlthau, K. A., van Exel, N. J., Kovacs, E., Bellando, J., et al. (2014). Predicting health utilities for children with autism spectrum disorders. Autism Research, 7, 649-663.

Petrou, S., \& Kupek, E. (2009). Estimating preference-based Health Utilities Index Mark 3 utility scores for childhood conditions in England and Scotland. Medical Decision Making, 29, 291-303.

Pregibon, D. (1980). Goodness of link tests for generalilzed linear models. Applied Statistics, 29, 15-24.

Prosser, L. A., Hammitt, J. K., \& Keren, R. (2007). Measuring health preferences for use in cost-utility and cost-benefit analyses of interventions in children: Theoretical and methodological considerations. Pharmacoeconomics, 25, 713-726.

Prosser, L. A., Lamarand, K., Gebremariam, A., \& Wittenberg, E. (2015). Measuring family HRQoL spillover effects using direct health utility assessment. Medical Decision Making, 35, 81-93.

Pullenayegum, E. M., Tarride, J. E., Xie, F., Goeree, R., Gerstein, H. C., \& O'Reilly, D. (2010). Analysis of health utility data when some subjects attain the upper bound of 1: Are Tobit and CLAD models appropriate? Value in Health, 13, 487-494.

Pyne, J. M., Sieber, W. J., David, K., Kaplan, R. M., Hyman, R. M., \& Keith, W. D. (2003). Use of the quality of well-being selfadministered version (QWB-SA) in assessing health-related quality of life in depressed patients. Journal of Affective Disorders, 76, 237-247.

Radloff, L. S. (1977). The CES-D Scale: A self-report Depression Scale for research in the general population. Applied Psychological Measurement, 1, 385-401.
Ramsey, J. (1969). Tests for specification error in classical linear least squares regression analysis. Journal of the Royal Statisical Society Series B, 31, 350-371.

Reed, H. E., McGrew, S. G., Artibee, K., Surdkya, K., Goldman, S. E., Frank, K., et al. (2009). Parent-based sleep education workshops in autism. Journal of Child Neurology, 24, 936-945.

Reynolds, A. M., \& Malow, B. A. (2011). Sleep and autism spectrum disorders. Pediatric Clinic of North America, 58, 685-698.

Rossignol, D. A., \& Frye, R. E. (2011). Melatonin in autism spectrum disorders: A systematic review and meta-analysis. Developmental Medicine and Child Neurology, 53, 783-792.

Shumway, S., Farmer, C., Thurm, A., Joseph, L., Black, D., \& Golden, C. (2012). The ADOS calibrated severity score: Relationship to phenotypic variables and stability over time. Autism Research, 5, 267-276.

Simonoff, E., Pickles, A., Charman, T., Chandler, S., Loucas, T., \& Baird, G. (2008). Psychiatric disorders in children with autism spectrum disorders: Prevalence, comorbidity, and associated factors in a population-derived sample. Journal of American Academy of Child Adolescent Psychiatry, 47, 921-929.

Smith-Olinde, L., Grosse, S. D., Olinde, F., Martin, P. F., \& Tilford, J. M. (2008). Health state preference scores for children with permanent childhood hearing loss: A comparative analysis of the QWB and HUI3. Quality of Life Research, 17, 943-953.

Swanson, L. M., Arnedt, J. T., Rosekind, M. R., Belenky, G., Balkin, T. J., \& Drake, C. (2011). Sleep disorders and work performance: Findings from the 2008 National Sleep Foundation Sleep in America poll. Journal of Sleep Research, 20, 487-494.

The National Institute for Health and Care Excellence. (2013). Guide to the methods of technology appraisal 2013 London. England: The National Institute for Health and Care Excellence.

Tilford, J. M. \& Payakachat, N. (2014). Progress in measuring family spillover effects for economic evaluations. Expert Review of Pharmacoeconomics \& Outcomes Research, 16, 1-4.

Tilford, J. M., Payakachat, N., Kovacs, E., Pyne, J. M., Brouwer, W., Nick, T. G., et al. (2012). Preference-based health-related quality-of-life outcomes in children with autism spectrum disorders: A comparison of generic instruments. Pharmacoeconomics, 30, 661-679.

Ungar, W., \& Gerber, A. (2010). The uniqueness of child health and challenges to measuring costs and consequences. In W. Ungar (Ed.), Economic evaluation in child health. New York: Oxford University Press.

Weinstein, M., Siegel, J., Gold, M., Kamlet, M., \& Russell, L. (1996). Recommendations of the panel on cost-effectiveness in health and medicine. The Journal of the American Medical Association, 276, 1253-1258.

Wittenberg, E., \& Prosser, L. (2013). Disutility of illness for caregivers and families: A systematic review of the literature. Pharmacoeconomics, 31, 489-500.

Yang, Y., Brazier, J., \& Tsuchiya, A. (2014). Effect of adding a sleep dimension to the EQ-5D descriptive system: A "bolt-on" experiment. Medical Decision Making, 34, 42-53.

Zablotsky, B., Anderson, C., \& Law, P. (2013). The association between child autism symptomatology, maternal quality of life, and risk for depression. Journal of Autism and Developmental Disorders, 43, 1946-1955. 